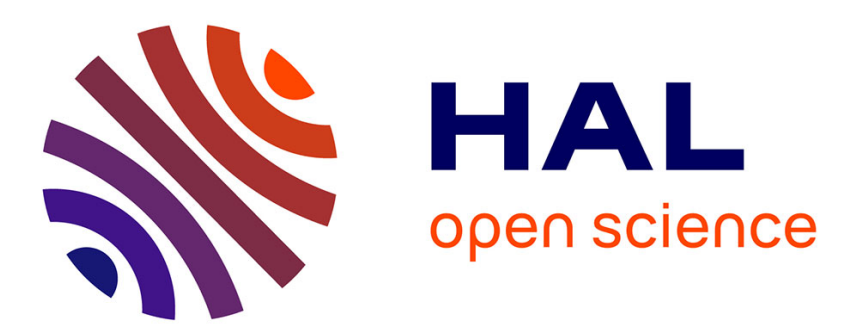

\title{
Analysis of compaction in brittle foam with multiscale indentation tests
}

A. Bouterf, E. Maire, S. Roux, François Hild, X. Brajer, E. Gouillart, E. Boller

\section{To cite this version:}

A. Bouterf, E. Maire, S. Roux, François Hild, X. Brajer, et al.. Analysis of compaction in brittle foam with multiscale indentation tests. Mechanics of Materials, 2018, 118, pp.22 - 30. 10.1016/j.mechmat.2017.12.004 . hal-01674574

\section{HAL Id: hal-01674574 https://hal.science/hal-01674574}

Submitted on 3 Jan 2018

HAL is a multi-disciplinary open access archive for the deposit and dissemination of scientific research documents, whether they are published or not. The documents may come from teaching and research institutions in France or abroad, or from public or private research centers.
L'archive ouverte pluridisciplinaire HAL, est destinée au dépôt et à la diffusion de documents scientifiques de niveau recherche, publiés ou non, émanant des établissements d'enseignement et de recherche français ou étrangers, des laboratoires publics ou privés. 


\title{
Analysis of compaction in brittle foam with multiscale indentation tests
}

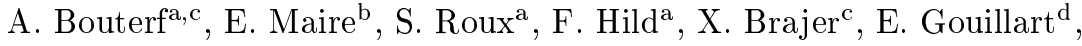 \\ E. Boller ${ }^{\mathrm{e}}$

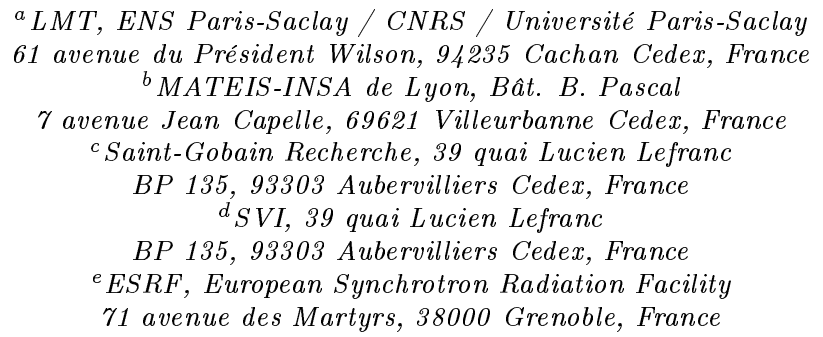

\begin{abstract}
Lightweight plasterboard is a product composed of "plaster foam" core whose porosity can reach $75 \mathrm{vol} \%$, lined with two sheets of paper. To optimize the trade-off between thermal resistance and mechanical strength, it is important to understand and characterize the mechanical behavior of plasterboard. Core compaction of plasterboard is one of the prevalent degradation mechanism. This mechanism is studied herein using in-situ indentation experiments performed at two different scales. The first test was carried out in a lab tomograph. The second test was conducted on the high resolution synchrotron ID19 beamline at ESRF. Very early damage is revealed. The basic mechanism of pore collapse and its gradual development is detected in contrast with mesoscale observations where compaction appears very abrupt.
\end{abstract}

Keywords: Digital volume correlation, lightweight plasterboard, in-situ indentation test, X-ray tomography 


\section{Introduction}

One of the most used brittle foams is lightweight plaster that constitutes the core material of plasterboards. Plasterboards are extensively used in the construction industry. To better master their functional properties, it is important to relate them to the material microstructure. These questions have motivated fire resistance $[1,2]$ or mechanical properties $[3,4,5]$ studies. Benouis [6] showed the orthotropic nature of gypsum board, which is a consequence of the tensile behavior of the paper. Recently, the first in-situ monitoring of plaster hydration using X-ray tomography was reported by Adrien et al. [7]. The authors showed that the size of hemihydrate particles had an influence both on the hydration kinetics and on the final microstructure of the set plaster. However, foamed plaster itself has received little attention as a structural part. Its mechanical behavior and fracture resistance are scarcely studied in the literature. Yet some mechanical properties (e.g., bending strength, nail pull resistance) are needed for partition wall, and therefore a good knowledge of the degradation of the mechanical properties of the plate is valuable. The aim of the present study is to analyze the degradation mechanisms of plasterboard during indentation tests.

Early works on the indentation of foams suggested that their response was largely controlled by their compressive strength $[8,9]$ and tear resistance [10]. The deformation of an aluminum foam is limited exclusively to the region directly below the indenter. This is related to the absence of lateral propagation of the deformation (i.e., Poisson's ratio close to zero [11]). The remainder of the sample remains in the elastic regime. The shape of the tip of the densified zone in spherical and flat indenter is hemispherical. Flat indenters lead to compacted volumes larger than with the spherical indenter and to lateral tearing of the material. Ramamurty et al. [12] demonstrated that properties such as 
shear strength and tear energy can be extracted from the use of cone indentation tests. Some studies have been published on the modeling of the indentation response of aluminum foam [13]. In this study, to mimic the mechanical behavior of cellular solids, 2D Voronoi tessellations are used. Cell walls are modeled as elasto-plastic, quadratic Timoshenko beam elements are used. It is assumed that all the cell walls in a microstructure have the same thickness.

However, brittle foams have received much less attention. Some relevant references were devoted to the indentation of porous rocks $[14,17,18]$. Leite and Ferland [17] conducted spherical indentation on artificial rocks consisting of mixture of industrial gypsum, sand, water and polystyrene spheres. The tested materials had a porosity ranging between 44 and 68 vol\%. The authors concluded that the formation of the compacted area under the indenter seemed to be the main factor controlling the indentation process in porous rocks, and that the extent of the compacted area was controlled partly by the porosity of the material and partly by the mechanical properties of the porous structure.

X-ray tomography was applied for monitoring the indentation of aluminum foams [19]. In this study tomographic observations at a resolution of $50 \mu \mathrm{m}$ per voxel showed that the shape of the densified area was approximately a spherical cap directly under the head of the indenter. Smith and Bay [20] used digital volume correlation (DVC) to quantify the distortions of aluminum foam and compared with simulated fields using an isotropic elastic finite element analysis. DVC was also used to determine the strain fields in spherical indentation tests on aluminum foam with closed and open cells [21]. Mostavafi et al. [22] carried out DVC analyses as well to study the fracture behavior on short notched bars made of nuclear graphite at a resolution of $8 \mu \mathrm{m}$ per voxel.

Recently, Clément et al. [23] determined the mechanical properties of porous ceramics by micro-spherical indentation test. They used porous plaster as a 
model material, with two levels of porosity ratios (i.e., 30 and $60 \mathrm{vol} \%$ ). In the same study an in-situ spherical indentation test was conducted via X-ray tomography. The formation of a densified area of hemispherical shape was observed under the indenter. In order to visualize the indented area with a higher resolution than X-ray tomography (i.e., $6 \mu \mathrm{m}$ per voxel), post-mortem SEM observations were performed. They revealed that in the densified material, a fine fragmentation of gypsum crystals had occurred to fill in the large pores. Mercury porosimetry confirmed that the large scale porosity had disappeared in the compacted material under the indentation zone. In parallel to these observations, a non-associated elastoplastic model based on Drucker-Prager criterion was calibrated using the force-penetration curves. Staub et al. [24] have extended the same protocol to a highly porous alumina ceramic used as catalyst carrier. A similar constitutive model was identified on indentation tests. However accounting for tensile strength and hydrostatic pressure tests implied further sophistication of the yield criterion to include a cap at high pressures, and a Rankine-type criterion for tensile tests. It is noteworthy that such modeling does not reproduce a sharp transition between compacted and pristine material, but rather a progressive one. SEM observations of a polished section passing through the imprint center of an indented sample show the formation of a hemispherical zone located beneath the indent, of about $60 \mu \mathrm{m}$ of radius, which seems denser than the bulk material. Closed pores induced by the crushing of the macroporosity was observed beneath the indent. However, the image cannot resolve the mesoporosity.

Saucedo-Mora et al. [25] reported Hertzian indentation of a $\mathrm{SiC} / \mathrm{SiC}$ composite. This in-situ test was monitored via high-resolution synchrotron X-ray tomography combined with three-dimensional displacement fields measured with digital volume correlation. It was again noted that a sharp transition is observed 
between the initial pristine state with a modest elastic strain, and the crushed material (at a resolution of $0.9 \mu \mathrm{m}$ per voxel). Small specimen tests, such as indentation, can be performed at elevated temperatures with irradiated materials, and are thus very useful to assess the material properties when operated in extreme conditions. The goal of this study was to predict damage development in nuclear materials. The measured data from these tests, such as displacement profiles, were used to validate the mechanical model (i.e., parameters of cohesive zone model) within a numerical approach accounting for a precise description of the actual 3D microstructure.

Further, Yadav et al. [26] conducted an experimental study of plane strain wedge indentation of a model porous brittle (gypsum samples, porosity of $49 \%$ ). Particle image velocimetry analyses of the images enabled the authors to analyze the resulting plastic zone in terms of velocity, strain rate, strain and volume changes (e.g., local pore collapse). Again, the pore-collapsed region appeared with a marked and abrupt boundary at a resolution of $10 \mu \mathrm{m}$ per pixel. A discussion based on a cavity expansion model that accounted for deviatoric and volumetric plastic strains gave an order of magnitude agreement with the observed data.

For foamed plaster, it was shown that Mohr-Coulomb model reproduced very well the global response of an indentation test. However a poorer prediction of the experimental crushed zone was observed. In particular, the transition between compacted plaster and its pristine state was not captured by the model, which predicted a very progressive transition rather than an abrupt one when monitored in-situ at a resolution of $12 \mu \mathrm{m}$ per voxel. For a macroscopic in-situ oedometric test it was found that a crushable foam model was fully consistent with the global response of the material. However, a uniform strain field was predicted, which was not observed experimentally at the same resolution as 
the indentation test. A constitutive law, which is consistent with the observed crushing mechanism, would consist of an elastic regime limited by Rankine's criterion, and followed by softening prior to secondary (hardening) densification [27].

From this literature review, it is concluded that only few studies focused on the mechanical characterization of brittle materials with high porosity through indentation tests. For highly porous materials, a densified zone ahead of the indenter appears. This local compaction capacity prevents the formation of indentation macrocracks leading to breakage in contrast with low porosity brittle solids. If several works mentioned or showed experimental evidence of a very sharp transition from pristine (undamaged) state to a region where macroporosity has collapsed at an average resolution of about $10 \mu \mathrm{m}$ per voxel, all reported modeling accounted for this transition through stable elastoplastic laws where the transition is smooth and smeared over a zone proportional to the indented region itself. Moreover, no experimental observation of the mechanism of pore collapse has been reported.

In the following, in-situ indentation tests will be conducted on two different scales. The goal is to refine the understanding of the compaction phase. The compaction mechanism will be discussed in terms of the indentation curve, tomographic observations and DVC analyses at two scales.

\section{Experimental procedure}

\subsection{Studied material}

Plasterboard is a flat sandwich composed of an internal element, i.e., foamed plaster, between two paper skins. The main function of the two paper layers is to withstand the tensile stresses and protect the core of the plate. They mainly contribute to the rigidity of the sandwiched board and support shear forces. 
For lighter plates the transition between its plaster core and the paper linings is provided by a dense layer of plaster, which is not foamed (referred to as "roller coating" or dense layer). Figure 1(a) shows a 3D rendering revealing the different components of plasterboard observed at micro-resolution (i.e., $1.4 \mu \mathrm{m}$ per voxel). Figure 1(b) displays the complex nanostructure of the core observed at a resolution of $25 \mathrm{~nm}$ per voxel. The latter clearly shows entangled gypsum needles. The porosity trapped between the crystal is also visible at this very high resolution. Both scans were acquired at the European Synchrotron Radiation Facility (ESRF, Grenoble, France); the first scan at beamline IDd19 and the second scan is a holotomographic reconstruction obtained at beamline ID22 NI for two different samples.

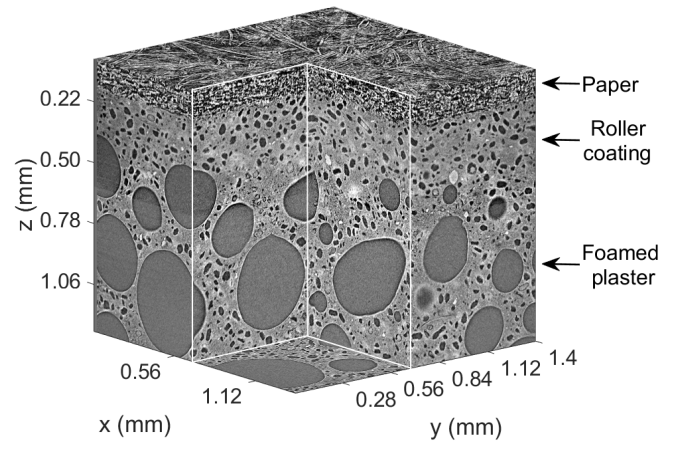

(a)

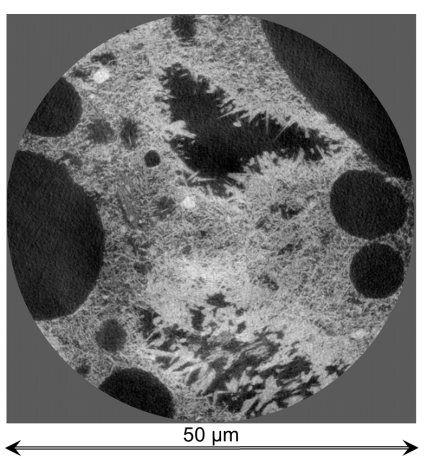

(b)

Figure 1: (a) Main components of lightweight plasterboard revealed thanks to a 3D tomographic rendering. (b) Nanostructure of the core observed at a resolution of $25 \mathrm{~nm}$

The present study was performed with dry gypsum. This condition is very important as it has been noticed that even a small amount of adsorbed water may drastically affect the mechanical behavior. Gypsum micro-crystal slip, which is promoted by water, and capillary forces tend to promote a plastic behavior as compared to a more brittle-like behavior in the dry state. 


\subsection{In-situ spherical indentation test}

The samples used in the experiments reported herein were prepared from industrial gypsum board. For the mesoscopic observations a cylinder $16 \mathrm{~mm}$ in diameter and $13 \mathrm{~mm}$ in height was machined (Figure 2).

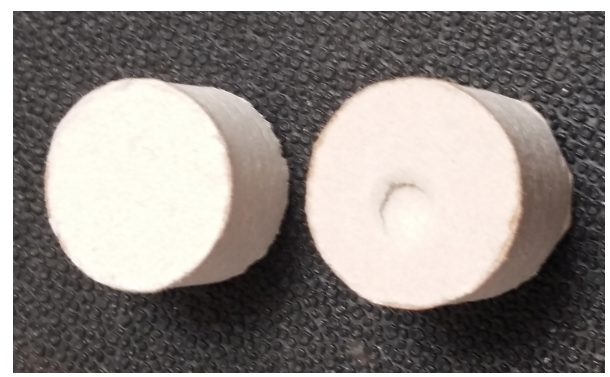

Figure 2: Sample used in the in-situ laboratory experiment. Plasterboard sample (left) before and (right) after indentation. The indentation mark is visible on the upper face of the sample after indentation

A glass spherical indenter $6 \mathrm{~mm}$ in diameter was chosen. The test was performed using the tension/compression machine developed at MATEIS laboratory (Lyon, France) [28] and designed to be mounted on turntables of various tomographs (Figure 3). To avoid obstruction of the X-ray beam by the testing machine during the $180^{\circ}$ rotation $\left(360^{\circ}\right.$ rotation in the lab tomograph), the load applied onto the spherical indenter is balanced by a tensile load on a cylindrical tube that encloses (without contact) the sample. This hollow cylinder is made of PMMA so that the X-ray absorption is weak and uniform regardless of its angular position. The displacement of the upper platen was provided by a stepping motor controlled by computer. The tests were considered as quasi-static since a very low stroke rate is selected (i.e., $5 \mu \mathrm{m} / \mathrm{s}$ ). 


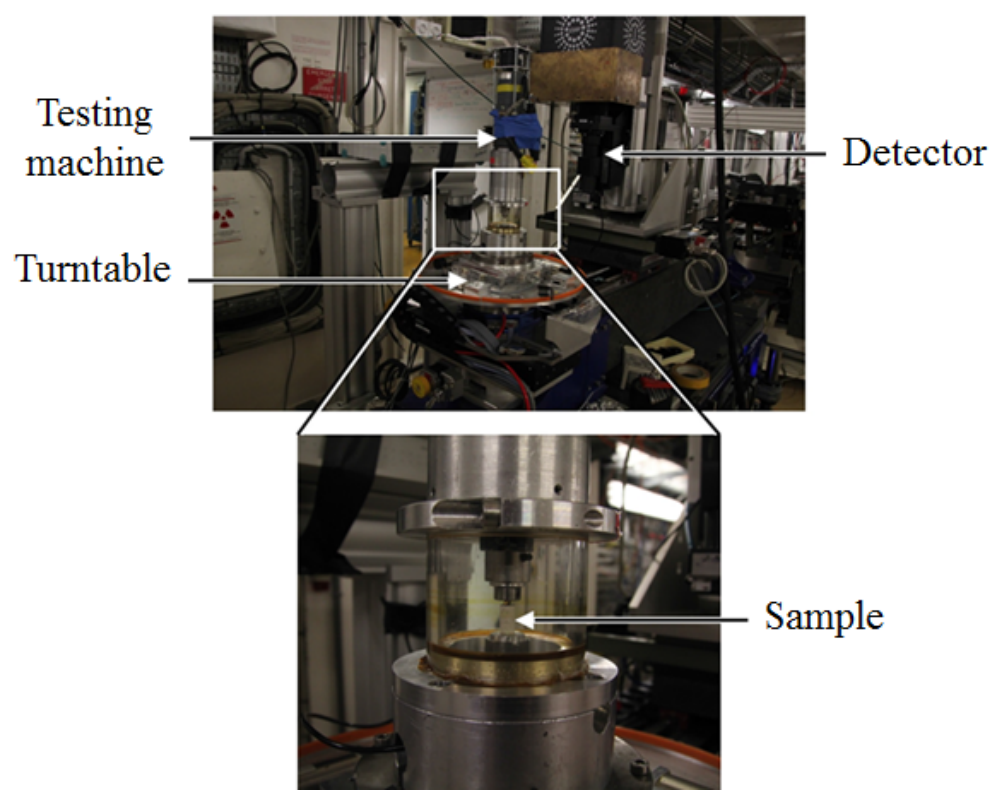

Figure 3: In-situ spherical indentation setup. Once the specimen has been mounted inside the PMMA tube, the indenter can be pushed through the specimen by an external actuator

The samples were imaged at the initial state (i.e., without load) and at several compressive loading levels. Closely spaced scans in terms of applied load (i.e., steps of about $5 \mathrm{~N}$ ) were performed to follow the development of the densified zone during the meso-test. After each load step, the displacement of the crosshead was interrupted, and the next scan is acquired after 20 minutes of dwell time to avoid blur due to the displacement of the sample during the relaxation process. The experiment was conducted at low resolution inside a Phoenix V Tome $\mathrm{X}^{\circledR}$ tomograph, using a source setting of $90 \mathrm{kV}, 220 \mu \mathrm{A}$ and a $1,920 \times 1,536$ pixel flat panel detector (see Ref. [28] for more details), physical voxel size of $12 \mu \mathrm{m} .900$ radiographs were acquired over the $360^{\circ}$ of rotation for each acquisition. The total duration of a single acquisition was approximately $35 \mathrm{~min}$. This first experiment will be hereafter referred to as the "meso-test."

In order to better understand the indentation mechanism in particular during 
the first steps of loading, in-situ spherical indentation was conducted on the high-resolution synchrotron beamline ID19 at ESRF. It will be referred to as "micro-test." The specimen was $7 \mathrm{~mm}$ in diameter and $13 \mathrm{~mm}$ high. A glass spherical indentor $3 \mathrm{~mm}$ in diameter was selected (Figure 4). The test was conducted with a very low stroke rate (i.e., $5 \mu \mathrm{m} / \mathrm{s})$.

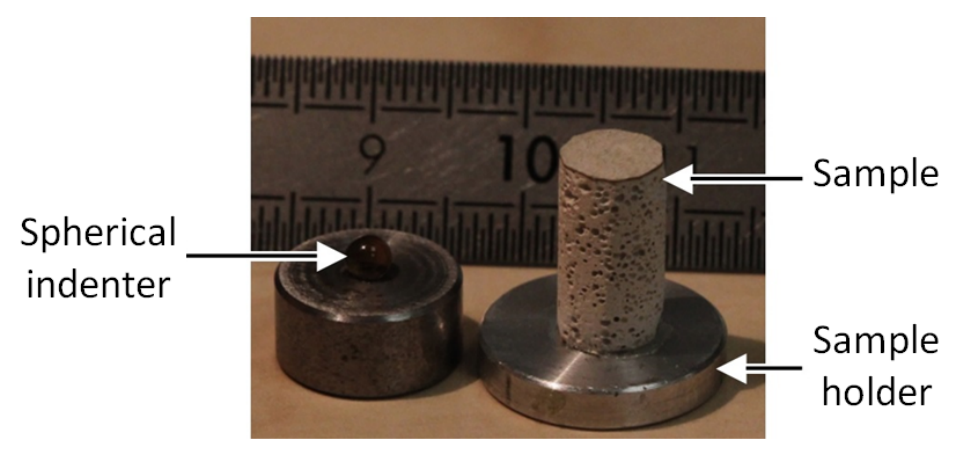

Figure 4: Sample and indenter used in the synchrotron (micro)experiment

The following acquisition parameters were selected: beam energy of $35 \mathrm{kV}$, electron current of $184 \mu \mathrm{A}$, physical voxel size of $1.4 \mu \mathrm{m}$. 2,000 radiographs were acquired during $180^{\circ}$ rotation for each scan. The total acquisition time lasted only about 6 minutes. The acquisitions were performed in a local tomography mode [16], namely, the imaged volume in the test is a cylinder $1.4 \mathrm{~mm}$ in diameter and $1.4 \mathrm{~mm}$ thick centered about the indenter axis and embedded in the larger sample. 3D volumes were reconstructed using a classical filtered back projection algorithm, with padding of the sinogram to avoid artifacts due to local tomography.

Figure 5 shows the history of load versus displacement of the indenter for the two tests. A quasi-linear dependence of the applied load to penetration depth is observed in both cases. The oscillations in the response are due to repeated cycles of the collapse of the porosity and densification during loading. 
A similar dependence was obtained for porous rocks [17], cemented carbide [29] and plaster [30, 27]. The aim of the following sections is to explain the (linear) macroscopic load vs. depth penetration response.

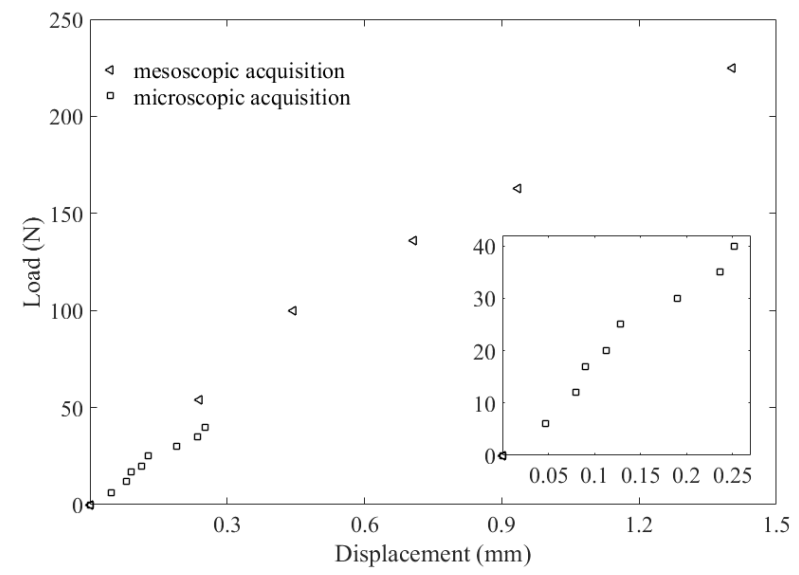

Figure 5: Load-displacement curve of the spherical indentation tests. A quasi-linear dependence of the applied load to the indentation depth is observed at both scales

\section{Multiscale observations}

In the sequel, mesoscale and microscale observations are reported. They will allow the degradation mechanisms to be revealed and discussed.

\subsection{Mesoscopic observations}

The changes of the mesostructure during the test is illustrated by $3 \mathrm{D}$ renderings of the sample at different load levels (Figure 6). 


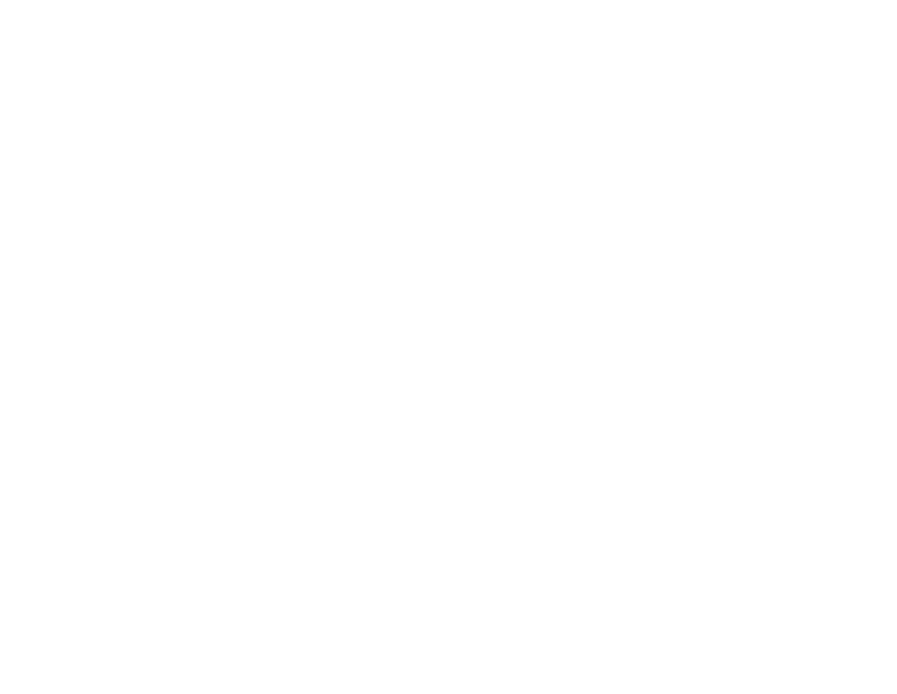

Figure 6: 3D rendering of the sample showing the deformed gray level mesostructure at the last load level (1 voxel $\leftrightarrow 12 \mu \mathrm{m})$. Online version: corresponding movie for the 6 scanned steps

It is found that the densified zone is located directly under the head of the indenter. Past a load of $135 \mathrm{~N}$ a semi-ellipsoidal shaped zone develops during the whole test. When the indenter has penetrated a sufficient depth, the load is essentially borne by the compacted gypsum area. Outside the compacted region, the mesostructure remains intact. After that load level, the crushed and compacted region under the head of the indenter acts as a quasi incompressible material that transmits the load to the surrounding pristine plaster [27]. Once the compacted area is fully developed, the shape of the indenter head is no longer involved in the indentation process $[41,27]$. The latter is completely controlled by the size and shape of the compacted zone.

Similar phenomena with comparable compacted zones have been observed in very porous refractory material (i.e., 65 vol\% porosity [14]), porous artificial rock [17] and aluminum foam [19, 20]. Recently the same observations were 
reported on porous plaster [30] and cemented carbide [29].

\subsection{Microscopic observations}

In order to better understand the compaction mechanism discussed in the previous section, especially the evolution of the compaction zone in the first step of loading, the micro-test is analyzed. Figure 7 shows 3D renderings of the deformed microstructure.

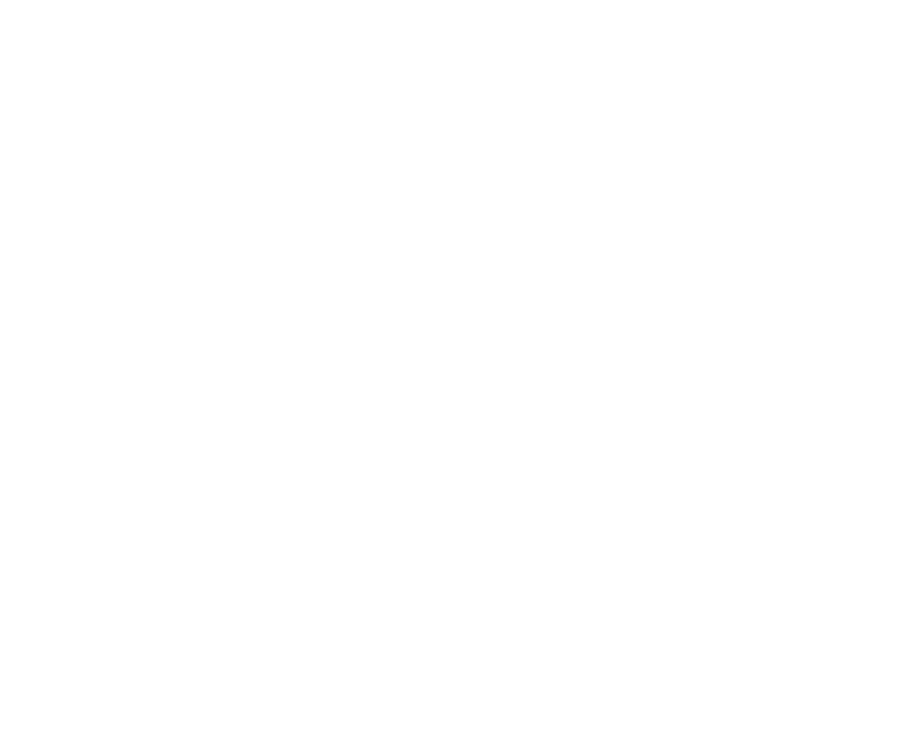

Figure 7: 3D rendering of the sample showing its deformed gray level microstructure at the last load level (1 voxel $\leftrightarrow 2.8 \mu \mathrm{m})$. Online version: corresponding movie for the 8 scanned steps

It is noted that until the third load level (i.e., $17 \mathrm{~N}$ ) no damage is visible in the plaster core. Conversely the paper under the indenter is significantly compressed. No signs of compaction are observed in the roller coating layer at this stage of loading.

From the fourth scan on, damage by cracking is observed in the dense plaster layer. Figure 8 shows a zoom of the damaged area. The crack appears near the core-roller coating interface. 


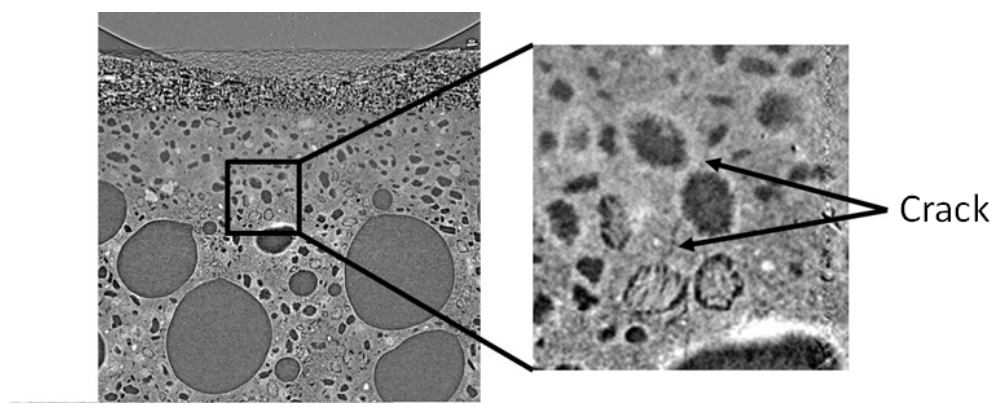

Figure 8: Sagittal tomographic section corresponding to the fourth scan (i.e., $F=20 \mathrm{~N}$ ) in Figure 7. Initiation of the first crack in the core of the plate near the interface between the core and the roller coating layer. The size of the section is $1.4 \times 1.4 \mathrm{~mm}^{2}$

For the fifth scan, cracking develops from the core-roller coating interface to the indenter and also to the foam. At this load level, the beginning of pore collapse in the core is observed. In particular the fracture of thin walls occurs between large bubbles. The last three scans clearly show the onset of a mesonetwork of cracks in the roller coating layer accompanied by the collapse of the meso-porosity of the upper part of the plaster core of the sample. To confirm these observations, digital volume correlation analyses are reported.

A schematized failure scenario of plasterboard in spherical indentation is shown at the microscale in Figure 9. The first damage event occurred when $F=20$ N. It consists of the initiation of the first microcracks (in red) in the roller coating accompanied by significant compression of the paper (green lines) under the indenter (blue line). The second step comprises the fracture of angled struts between large bubbles and the multiple microcracking of the roller coating (red lines and circles). The third step consists of the formation of a set of fragments (yellow parts) due to multiple microcracking and a set of strut fractures. Under the indenter these pushed fragments lead to the filling and crushing of the first layer of porous plaster (yellow arrows). 


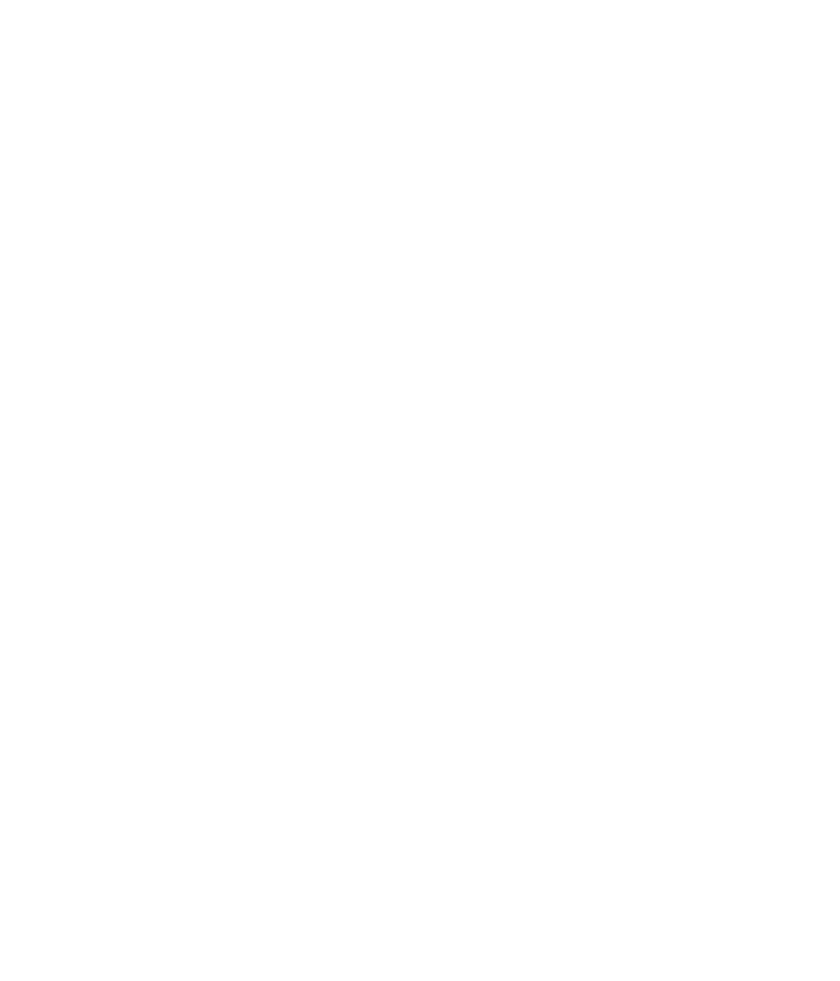

Figure 9: Sagittal tomographic sections of the sample at different load levels in the microindentation test. Failure scenario of plasterboard when $F=40$ N. Online version: corresponding movie for the 8 scanned steps

\section{Digital volume correlation analyses}

The reconstructed volumes can be quantitatively explored by Digital Volume Correlation (DVC) $[31,32]$ to measure the displacement fields in the volume of the imaged sample thanks to the very heterogeneous texture of plaster (Figure 1). DVC is the 3D extension of digital image correlation [33] whereby displacement fields are measured by registering the volume in the deformed configuration with that in the reference state. Being based on 3D tomographic images, DVC provides three dimensional displacement fields. In the present case, continuous displacement fields are measured when discretized over a finite 
element mesh made of 8-noded (C8) cubes (i.e., C8-DVC [34]).

Recently, regularized digital volume correlation $[35,36,37]$ was introduced for measuring very small 3D displacements. Regularized DVC makes use of constitutive laws and helps correlation registration to converge even in the close to zero-gradient gray level zones. By tuning the regularization length more or less smooth displacement fields are measured. In strongly regularized solutions, high spatial frequencies are filtered out when not mechanically admissible as part of an elastic solution. Special care should be exercised when dealing with localized phenomena, namely, the regularization lengths should be made as small as possible [37] or tailored to the presence of cracks [39]. In the present case, only modest regularization lengths will be considered (i.e., twice the element size). The displacement at the $n$-th volume is evaluated from the initial volume (nondeformed state, considered as reference). For the microsample, the tomographic data at different loading levels are aggregated by a factor of 0.5 to make the analysis more tractable. After aggregation, the Region Of Interest (ROI) has a size of $448 \times 448 \times 400$ voxels $^{3}$ or $1254 \times 1254 \times 1120 \mu \mathrm{m}^{3}$. The size of the $\mathrm{C} 8$ elements is 16 voxels (or $45 \mu \mathrm{m}$ ). The regularization length $\ell_{\text {reg }}$ is equal to 32 voxels (or $90 \mu \mathrm{m}$ ). For the mesosample, the ROI has a size of $416 \times 416 \times 288$ voxels $^{3}$ or $5 \times 5 \times 3.46 \mathrm{~mm}^{3}$. The size of the $\mathrm{C} 8$ elements is 16 voxels (or $192 \mu \mathrm{m}$ ). The regularization length $\ell_{\text {reg }}$ is equal to 32 voxels (or $384 \mu \mathrm{m})$.

In the present case, the first focus will be put on the registration (or correlation) residual field. The latter is obtained by computing the gray level difference of the volume in the reference configuration and the volume in the deformed configuration corrected by the measured displacement field. The advantage of such a field is to reveal all the violations of gray level conservation $[38,39]$. In the present case it will correspond to the compacted zone and mesocracking. 
Displacement and strain fields will then be analyzed.

\subsection{Mesoscale analysis}

Figure 10 shows 3D renderings of the correlation residuals. For the first loading step (i.e., $F=54 \mathrm{~N}$ ), a very small zone is revealed, which corresponds to the onset of meso-compaction. In that zone, because of pore collapse, the gray level conservation is no longer satisfied. Apart from this zone, the correlation residuals have very small levels (i.e., RMS level is very close to that observed when no motion was applied to the sample). The elastic correction is then very good since no mesocracks are detected. From all these observations, it is concluded that the first step of the meso-test is associated with an elastic response of plasterboard and meso-compaction very close to the upper paper lining. For the subsequent scans, it is observed that the crushed zone develops and that a macrocrack appears when $F=225 \mathrm{~N}$. However, the latter does not propagate in an unstable manner. Consequently, the linear load vs. depth of penetration response of the material (Figure 5) corresponds to the gradual growth of the crushed zone inducted by the indentation test. This observation is consistent with reported results for resolutions of $12 \mu \mathrm{m}$ per voxel [41, 27].

The gray level residual maps provide a very good estimator of the size and shape of the compacted zone because they resolve voxel scale features, which allows for a fine description of the boundary between the compacted zone and the rest of the sample. These maps provide an objective check of the quality of the measurement and make it possible to judge whether the hypothesis of an elastic behavior of plaster outside the compacted zone is consistent with observation (i.e., no sign of deviation of linear elasticity is observed outside the crushed zone). 


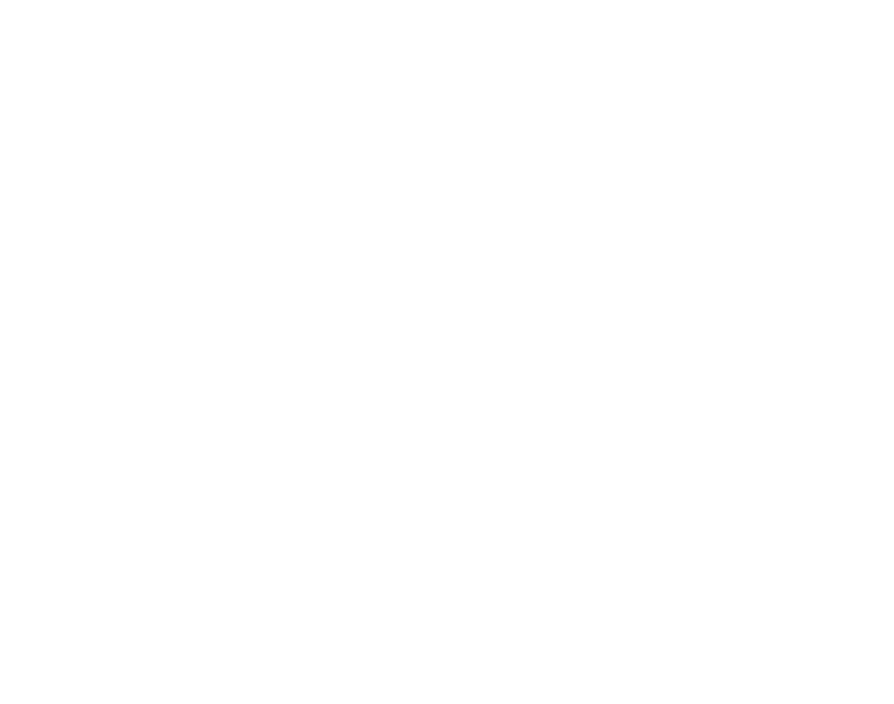

Figure 10: 3D rendering of correlation residual (in gray levels) for the last loading step of the meso-indentation test ( 1 voxel $\leftrightarrow 12 \mu \mathrm{m}$ ). Online version: corresponding movie for the 5 analyzed steps. The fields are expressed in gray levels

Figure 11 shows 3D renderings of the displacement field in the loading direction for the 5 analyzed steps. As the crushed region has lost its microstructure, this region is masked from the DVC analysis and the displacement field remains undetermined there. It is worth noting that the locations where the gray level residuals are greater than 50 have been masked. The mask is adjusted as being the smallest semi-ellipsoid that contains the compacted region. Outside the compacted zone plaster remains mostly elastic and a modest range of displacement magnitude was measured (i.e., less than 2 voxels). In the elastic domain, displacements and strains are expected to decrease with $r$, where $r$ is the distance to the indentor center. This very rapid decrease of displacement with $r$ is clearly observed on the displacement maps. when $F=225 \mathrm{~N}$, the displacement map shows that a macrocrack appears near to the interface between the roller coating and the core of the sample. 


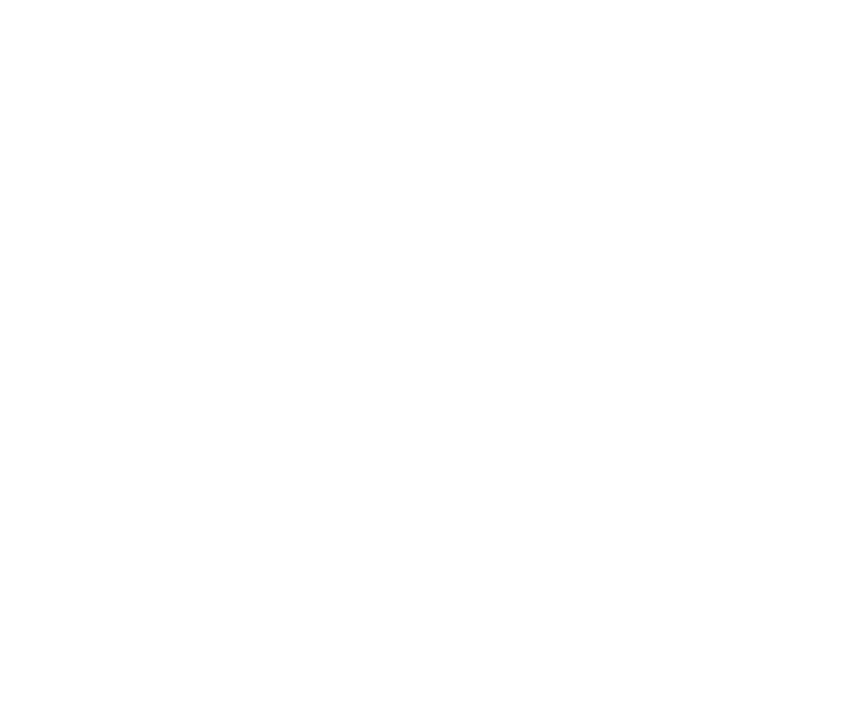

Figure 11: 3D rendering of vertical displacement field for the last loading step of the mesoindentation test. Online version: corresponding movie for the 5 analyzed steps. The fields are expressed in voxels $(1$ voxel $\leftrightarrow 12 \mu \mathrm{m})$

Figure 12 shows $3 \mathrm{D}$ renderings of the major eigen strain field (in \%) for the 5 analyzed steps. As for the displacement field the locations where the gray level residuals are greater than 50 have been masked. The major positive eigen strain is a scalar invariant that is very suited to reveal crack formations [39] irrespective of their orientation. Outside of the crushed zone, the amplitude of the major positive eigen strain measured by RC8-DVC is very low. As previously discussed, in the elastic domain, strains are expected to decay as $1 / r^{2}$ where $r$ is the distance to the indentor center. At the last load step (i.e., $F=225 \mathrm{~N}$ ), the presence of the macrocrack near the interface between the roller-coating and the sample core is also observed. 


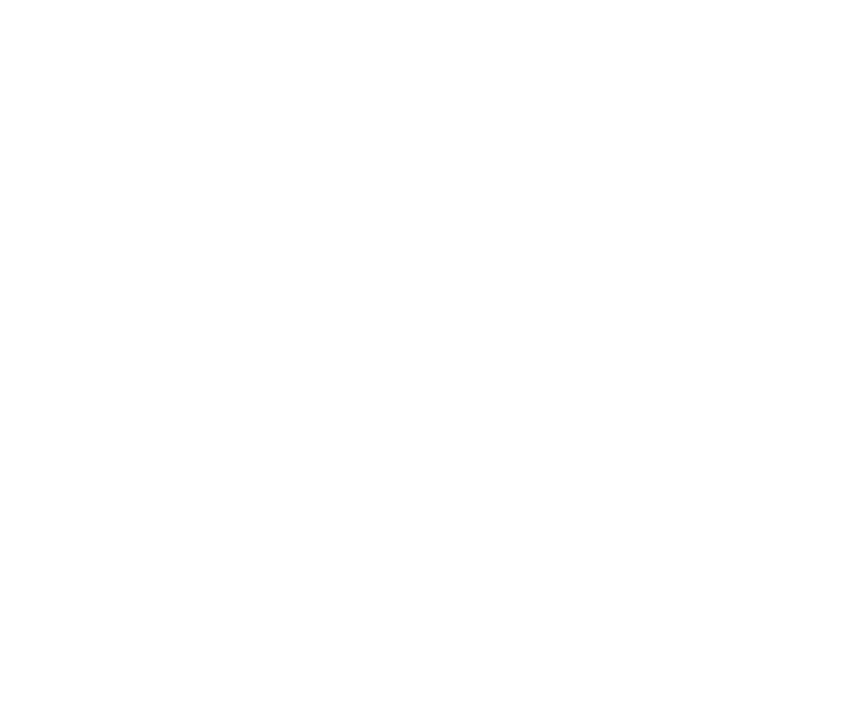

Figure 12: 3D rendering of major eigen strain (in \%) for the last loading step of the mesoindentation test ( 1 voxel $\leftrightarrow 12 \mu \mathrm{m})$. Online version: corresponding movie for the 5 analyzed steps

\subsection{Microscale analysis}

The same type of analysis is performed at the microscale. The analysis focuses on the roller-coating and the core of the plate, the DVC results shown in this section do not concern paper. The correlation residual fields are shown in Figure 13, ring artifacts are also visible. This proves that the registration has not been trapped by these rings. For the first three loading steps, no major deviations are observed, thereby indicating that the registration was successful everywhere within the analyzed ROI. For the last analyzed load level (i.e., $F=25 \mathrm{~N}$ ), it is observed that a network of cracks in the form of a Hertzian cone crack develops in the roller coating [15]. The RMS correlation residual is equal to 15 gray levels, which remains low in comparison with the maximum gray level (256) for the first step of loading and increases up to 18 gray levels at the last loading step. All these microcracks then induce pore collapse that 
leads to the development of a crushed zone under the indenter.

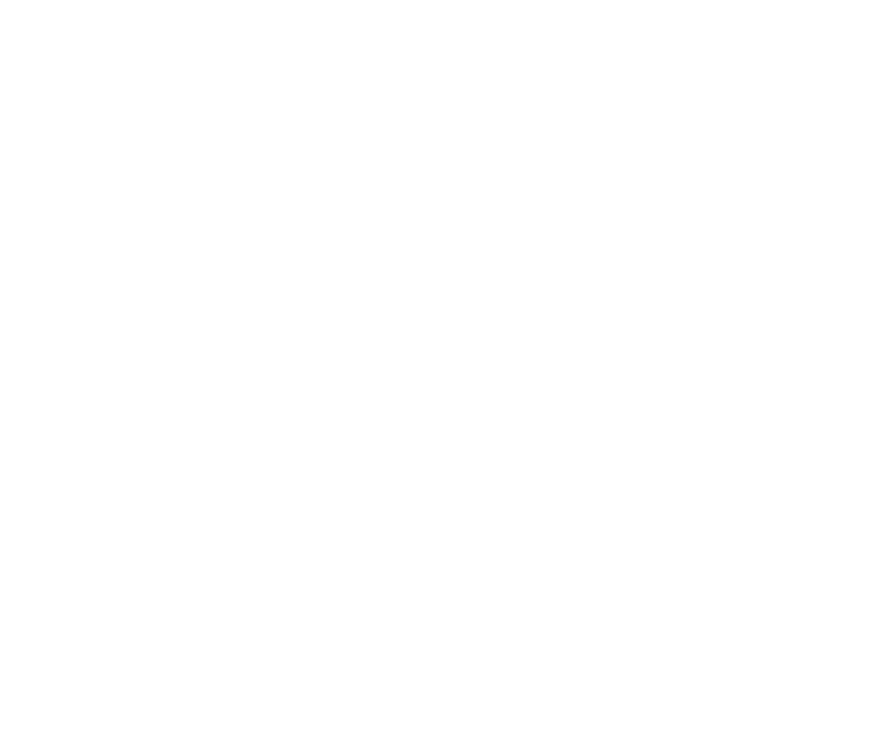

Figure 13: 3D rendering of correlation residuals (in gray levels) when the applied load $F=$ $25 \mathrm{~N}$ in the micro-indentation test. Online version: corresponding movie for the first four loading steps. The fields are expressed in gray levels ( 1 voxel $\leftrightarrow 2.8 \mu \mathrm{m}$ )

Figure 14 shows 3D renderings of the displacement field in the loading direction for the 4 analyzed steps. Up to $F=17 \mathrm{~N}$ the displacement maps show that the sample underwent mostly rigid body motions. At this late stage of loading, no crack is detected on the displacement field. When $F=20 \mathrm{~N}$, the measured displacement field presents a slight discontinuity at the interface between the roller coating and the sample core. The displacement field measured from the last analyzed scan, $F=25 \mathrm{~N}$, has a totally different pattern as compared with the previous maps. Steep displacement gradients indicative of discontinuities are clearly observed, which show the presence of a crack network. 


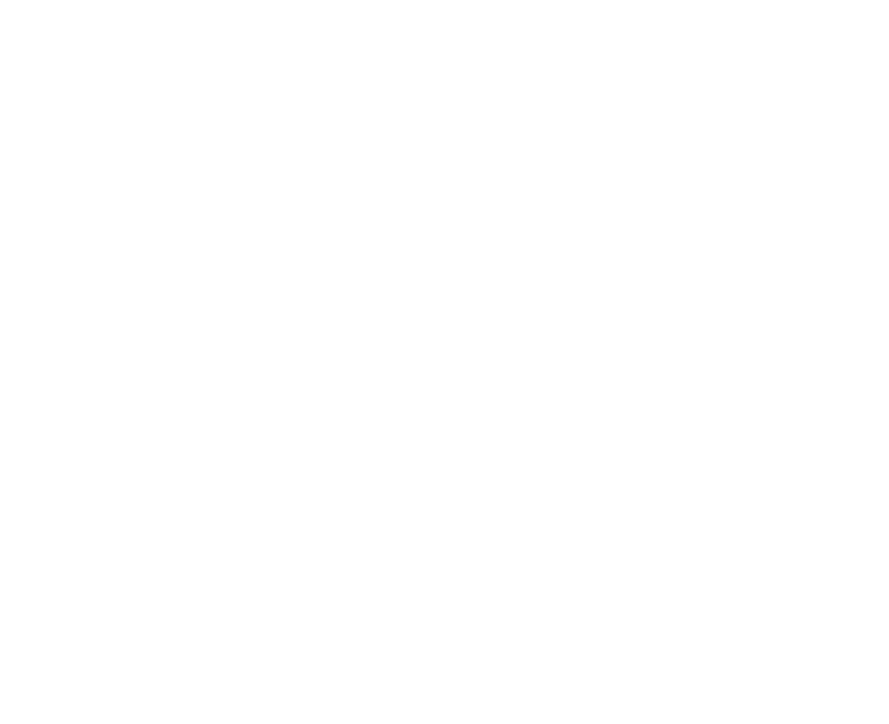

Figure 14: 3D rendering of vertical displacement field for the last analyzed step of the microindentation test. Online version: corresponding movie for the 4 analyzed steps. The fields are expressed in voxels $(1$ voxel $\leftrightarrow 2.8 \mu \mathrm{m})$

Figure 15 shows $3 \mathrm{D}$ renderings of the major eigen strain field for the 4 analyzed steps obtained from DVC analysis. Up to $F=17 \mathrm{~N}$, the amplitude of the major positive eigen strain measured by RC8-DVC is very low (i.e., less than $1 \%$ ). When $F=20 \mathrm{~N}$, slight localization is observed in the strain map at the interface between the roller coating and the sample core. When $F=25 \mathrm{~N}$, the highest strain levels are clearly visible and reflect the presence of cracks, which cannot be totally resolved as continuous displacements are sought. This result shows that DVC is able to mark precisely the crack pattern in spite of its complex shape. 


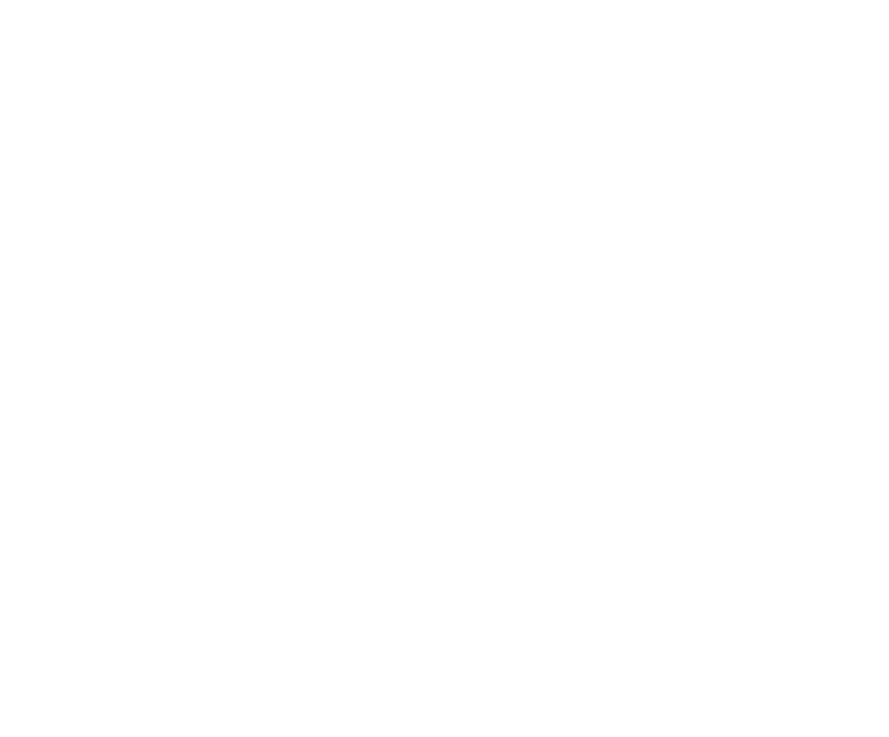

Figure 15: 3D rendering of major eigen strain (in \%) for the last analyzed step of the microindentation test ( 1 voxel $\leftrightarrow 2.8 \mu \mathrm{m}$ ). Online version: corresponding movie for the 4 analyzed steps

The analysis of the microscopic indentation test showed that the roller coating was damaged (i.e., many microcracks are observed). In order to better understand how such mechanism develops, the following analysis only focuses on the behavior of the roller coating when $F=25 \mathrm{~N}$. DVC is run at the original scale (i.e., without voxel aggregation). Figures $16(\mathrm{a}-\mathrm{b})$ show $3 \mathrm{D}$ renderings of the deformed microstructure and the corresponding gray level residuals. From these pictures, the presence of a cone crack is visible. It is confirmed when analyzing the vertical displacement field (Figure 16(c)) and more importantly the major eigen strain field (Figure 16(d)). 


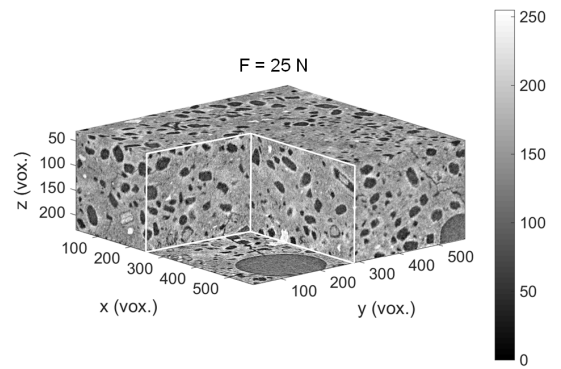

(a)

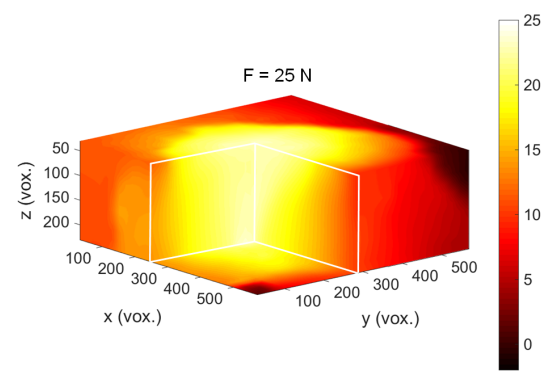

(c)

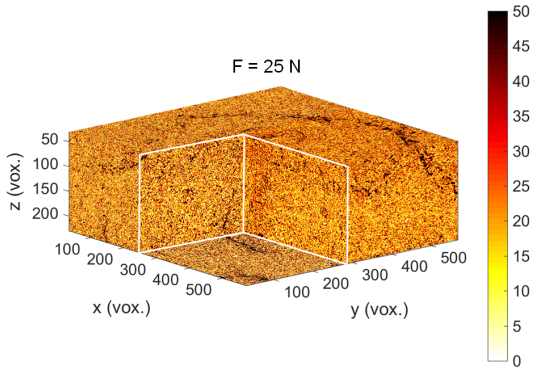

(b)

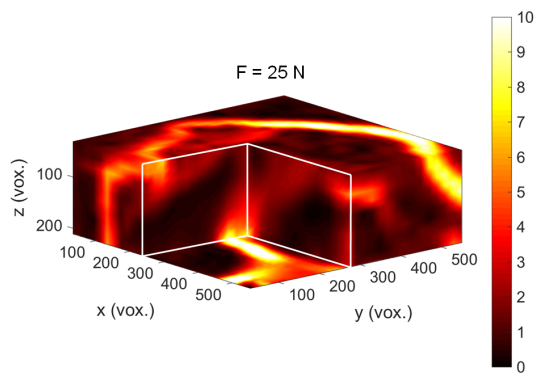

(d)

Figure 16: 3D renderings of the sample showing (a) the deformed gray level microstructure of the roller coating, (b) the gray level residuals, (c) the displacement field in the vertical direction expressed in voxels (1 voxel $\leftrightarrow 1.4 \mu \mathrm{m}$ ), and (d) the major eigen strain (in \%) field when $F=25 \mathrm{~N}$

\subsection{Discussion}

The mesoscale tomographic observations show the formation of a compacted area directly under the head of the indenter and lead to the conclusion that the indentation mechanism proceeds by the growth of the collapsed porosity domain, while the remainder of the sample can be considered as undamaged. A similar mechanism was observed in metal foams [20, 19], as well as porous rocks $[14,17,18]$, porous sintered alumina used as catalyst carrier [24], ceramic matrix composites [25] and high porosity gypsum [23, 30, 41, 26, 27]. 
In the case of metal foams, although the behavior of the solid skeleton is essentially plastic, the collapse of an individual pore involves a geometrical instability or buckling that locally softens the behavior until contacts between the pore walls restore a higher stiffness after most of the pore volume has disappeared. Thus even if the behavior of the wall material is (elasto)plastic, pore collapse can be seen macroscopically as a brittle failure event. In that respect the difference between metal and ceramic foams tend to disappear at a large scale.

Similarly, because the compressibility stiffness is restored after pore collapse (whether wall fragments partially fill the pore or not), these events are accompanied by an elementary volumetric plastic strain. If some shear stress were supported by the solid skeleton prior to collapse, it is likely to be relaxed in the transition. Hence macroscopically, the pore collapse phenomenon - even if composed of elementary unstable (plastic or brittle) events — looks like plasticity, with irreversible plastic strain occurring for a specific stress criterion. Hence, the key ingredient here is dictated by the material being a foam rather than the mechanical behavior of its wall constituent.

In spite of the ubiquity of pore collapse phenomena in foams, and its observed sharp boundary with the surrounding pristine material, modeling attempts tend to resort to a plasticity law that leads to a smeared transition zone [23, 30, 24]. It was argued [27] that a constitutive law comprising a softening branch is a sufficient condition to naturally provide such an abrupt pore-collapsed/pristine transition, albeit such laws are inconvenient from a numerical standpoint. The present study confirms at a mesoscopic scale that indeed the transition is very abrupt.

To the authors' knowledge, no former experimental work tried to reveal the microscopic mechanisms that were at the origin of pore collapse, so that all 
modeling attempts were compelled to rely on a phenomenological description. For instance, when characterizing the response of porous alumina samples to various mechanical tests, Staub et al. [24] had to introduce several yield criteria, namely, Drucker-Prager law, a cap for large hydrostatic pressures, and Rankine stress for uniaxial tensile tests. It is natural in this context to wonder whether these three criteria correspond to different elementary mechanisms, or simply one, in which case, homogenization of a microscopic geometrical description may provide a unique criterion.

The microscopic indentation test gives access to the mechanism responsible for pore collapse. At this scale, some fore-signs of pore collapse are visible. The initiation of microcracks and their propagation through skeleton walls is evidenced at this high magnification. What used to be an abrupt transition now appears more gradual. Although the initiation and early growth of the microcracks does not imply a much enhanced strain level, these microcracks open the way to fragmentation of the solid skeleton. Only at a later stage does this fragmentation massively occur leading to mesoscopic phase separation between the weakly damaged region where only some microcracks are present but barely visible, and the collapsed regime where all large pores are collapsed into a dense material where cohesion results from the attractive van der Vaals surface forces. Moreover, as expected for a brittle material, these microcracks appear to open in mode I with the walls of the gypsum foam. They seem to be arrested by pores, which smear out the stress concentration, and hence they do not appear as harmful as they may be for a dense gypsum material. Moreover, the very same microcracks are expected to initiate in a tensile test, indentation or hydrostatic compression. Only, their stable or unstable character varies from one type of test to the next. However, because the same type of microcracks appears to be responsible for the occurrence of the different damage 
manifestations it is natural to look for a unified criterion limiting the elastic domain rather than distinct ones for what may be seen as different macroscopic damage modes. Such criterion should result from a homogenization of mode I microcracks initiating within the solid walls. This statement is a consequence of the above high resolution observations, but could not be inferred from mesoor macroscale observations.

To the authors' knowledge no information about in-situ spherical indentation at micrometer scale is available for porous plaster with the porosity levels considered in this study (i.e., more than $75 \%$ ). The closest available data focus on porous plaster up to $56 \%$ porosity $[23,30]$. In these recent studies, the densification phenomenon was illustrated by using in-situ spherical indentation on plaster. The formation of a densified area of hemispherical shape was observed under the indentor (with a resolution of $6 \mu \mathrm{m}$ per voxel). In the same study, in order to visualize the indented area with a higher resolution than X-ray tomography, the authors used the "bonded-interface technique" [40]. SEM observations made after the spherical indentation test reveal a densification in the indented area. This densification appears to occur by accumulation of broken bits of gypsum crystals $[23,30]$. It is not possible to tell from the SEM observations if the phenomenon of slips between crystals is active, as has already been noted on plaster in a wet state [5]. The present study focuses on in-situ core compaction of plasterboard using X-ray tomography and DVC at two scales of observation. The analysis of the tomographic data supported by DVC results allowed the first steps of the compaction mechanisms to be understood and a failure scenario of plasterboard to be proposed. 


\section{Conclusions and perspectives}

Two spherical indentation experiments were conducted on lightweight plasterboard cylinders. The first test was carried out in a lab tomograph. Tomographic observations have shown the formation of a compacted zone directly under the indenter and have led to the conclusion that the indentation mechanism proceeded by the growth of the field of collapsed porosity, while the rest of the sample could be considered as undamaged. At such a mesoscopic scale, foamed plaster exhibits an abrupt transition from its pristine state to a compacted state where the large pores have disappeared.

In order to better understand the compaction mechanism a second test was performed in a synchrotron beamline at micrometer resolution. The latter allowed very early damage to be revealed. It consists of microcracks at the roller coating-core interface, and particularly close to the largest pores. As these microcracks form and develop, the large pores are progressively filled by small fragments of the solid walls as they are crushed. These high magnification images reveal the basic mechanisms of pore collapse and their progressiveness. This is to be contrasted with the mesoscale resolution where compaction appears as an abrupt transition, and without measurable foresigns of damage prior to pore collapse.

Tomographic data are also exploited by regularized digital volume correlation. In the present case, more than the measured kinematics, the correlation residuals further support the scenario that can be constructed from visual analyses of the acquired scans. The microstructure is erased in areas where the registration was successful. In contrast, the zones where gray level conservation is violated reveal the first signs of damage, which correspond to microcracking of the roller coating in the form of a Hertzian cone crack. It is also observed that the paper has undergone a strong through thickness compaction under the 
indenter.

All these analyses show that the linearity of the macroscopic load vs. depth of indenter penetration is explained by the development of a crushed zone, itself the result of cracking of the roller coating followed by the compaction of the plaster core. The stable growth of this compacted region is key for the material to withstand indentation. Interestingly, the basic mechanism at play for pore collapse appears to be pure mode I microcracks developing in the gypsum walls. These same microscopic defects are expected to be at play for hydrostatic compression as well as for tensile tests, thus calling for a unified description of the macroscopic damage mechanisms.

\section{Acknowledgements}

The authors wish to thank Saint-Gobain Recherche for supporting this research project, and particularly Dr. René Gy. The authors would also like to thank Dr. Sylvain Meille for helpful discussions and Jérôme Adrien for his help

during X-ray lab tomography. AB was financially supported by ANRT through contract no. 2010/567. We also acknowledge the European Synchrotron Radiation Facility support for experiment no. MA-1281. We would like to thank Dr. Peter Cloetens for his help during acquisition at beamline ID22 NI. The support of ANR "EDDAM" project (ANR-11-BS09-027) is also gratefully acknowledged.

\section{References}

[1] Sakji, M.S. Comportement thermomécanique avec endommagement d'une plaque multicouche carton-plâtre-carton soumise au feu. PhD thesis, University of Marne-La-Vallée (France), 2006. 
[2] Payraudeau-Le Roux, N., Meille, S., Chevalier, J., Maire, E., Adrien, J. In situ observation of plaster microstructure evolution during thermal loading. Fire and Materials, 2016. doi $=10.1002 /$ fam.2357.

[3] Murat, M., Pusztaszeri, L., Gremion, M. Corrélation texture cristallinepropriétés mécaniques de plâtres durcis, étude préliminaire. Mat. Construc., 47(8), 337-385, 1974.

[4] Coquard, P. Résistance mécanique des plâtres secs et humides. PhD thesis, University of Aix-Marseille III (France), 1992.

[5] Meille, S. Etude du comportement mécanique du plâtre pris en relation avec sa microstructure. PhD thesis, INSA de Lyon (France), 2001.

[6] Benouis, A. Comportement mécanique des ouvrages en plaques de plâtre sur ossature métallique. PhD thesis, Ecole Nationale des Ponts et Chaussées (France), 1995.

[7] Adrien, J., Meille, S., Tadier, S., Maire, E., Sasaki, L. In-situ X-ray tomographic monitoring of gypsum plaster setting. Cement Concr. Res., 82, 107-116, 2016.

[8] Shaw, MC., Sata, T. The plastic behavior of cellular materials. Int. J. Mech. Sci., 8(7), 469-478, 1966.

[9] M., Wilsea, K.L., Johnson, M.F., Ashby. Indentation of foamed plastics. Int. J. Mech. Sci., 17(7), 457-460, 1975.

[10] Olurin, O.B., Fleck, N.A., Ashby M.F. Indentation resistance of an aluminium foam. Scripta Materialia, 43, 983-989, 2000.

[11] Kumar, P.S., Ramachandra, S., Ramamurty, U. Effect of displacement-rate on the indentation behavior of an aluminum foam. Mat. Sci. Eng., A347, 330-337, 2003. 
[12] Ramamurty U., Kumaran, M.C. Mechanical property extraction through conical indentation of a closed-cell aluminum foam. Acta Materialia, 52, 181-89, 2004.

[13] Tekoglu, C., Pardoen, T., Gibson, L.J., Onck, P.R. Size effects in foams: Experiments and modeling. Proc. Mat. Sci, 56, 109-138, 2011.

[14] Suárez-Rivera, F.R., Cook, N.G., Cooper, G.A., Zheng, Z. Indentation by pore collapse in porous rocks. Proc. 31st US Symp. on Rock Mech., 671-678, 1990.

[15] A. C. Fischer-Cripps, Introduction to Contact Mechanics. Mechanical Engineering Series, Chapter 7, 115-136, (Springer, New York, 2007).

[16] Elliott, J.A., Windle, A.H., Hobdell, J.R., Eeckhaut, G., Oldman, R.J., Ludwig, W., Boller, E., Baruchel, J. In-situ deformation of an open-cell flexible polyurethane foam characterised by 3D computed microtomography. Journal of Materials Science, 37, 1-9, 2002.

[17] Leite, M.H, Ferland, F. Determination of unconfined compressive strength and Young's modulus of porous materials by indentation tests. Eng. Geolog., 59, 267-280, 2001.

[18] Magnenet, V., Giraud, A., Homand, F. Parameter sensitivity analysis for a Drucker-Prager model following from numerical simulations of indentation tests. Comput. Mater. Sci., 44, 385-91, 2008.

[19] Kádár, Cs., Maire, E., Borbély, A., Peix, G., Lendvai, J., Rajkovits, Zs. Xray tomography and finite element simulation of the indentation behavior of metal foams. Mat. Sci. Eng, A387-389, 321-325, 2004.

[20] Smith, T.S., Bay, B.K. Experimental Measurement of Strains using Digital Volume Correlation. In Nontraditional Methods of Sensing Stress, Strain, 
and Damage in Materials and Structures: Second Volume, ASTM STP 1323, G.F., Lucas, P.C. McKeighan, and J.S. Ransom, Eds., American Society for Testing and Materials, West Conshohocken, Pa (USA), 2001.

[21] Bay, B.K. Methods and applications of digital volume correlation. J. Strain Anal., 43, 745-760, 2008.

[22] Mostafavi, M., McDonald, S.A., Mummery, P.M., Marrow, T.J. Observation and quantification of three-dimensional crack propagation in polygranular graphite. Eng. Fract. Mech, 110, 410-420, 2013.

[23] Clément, P., Meille, S., Chevalier, J., Olagnon, C. Mechanical characterization of highly porous inorganic solids materials by instrumented microindentation. Acta Mat., 61, 6649-6660, 2013.

[24] Staub, D., Meille, S., Le Corre, V., Rouleau, L., J. Chevalier, J. Identification of a damage criterion of a highly porous alumina ceramic. Acta Mat., 107, 261-272, 2016.

[25] Saucedo-Mora, L., Mostafavi, M., Khoshkhou, D., Reinhard, C., Atwood, R., Zhao, S., Connolly, B., Marrow, T.J. Observation and simulation of indentation damage in a $\mathrm{SiC}-\mathrm{SiC}_{\text {fibre }}$ ceramic matrix composite. Finite Elements in Analysis and Design, 110, 11-19, 2016.

[26] Yadav,S., Saldana, C., Murthy, T.G. Deformation field evolution in indentation of a porous brittle solid. Int. J. Solids Struct., 66, 35-45, 2015.

[27] Bouterf, A., Adrien, J., Maire, E., Brajer, X., Hild, F., Roux, S. Identification of the Crushing Behavior of Brittle Foam: From Indentation to Oedometric Tests. J. Mech. Phys. Sol., 98, 181-200, 2017.

[28] Buffière, J. Y., Maire, E., Adrien, J., Masse, J. P, Boller, E. In Situ 
Experiments with X ray Tomography: An Attractive Tool for Experimental Mechanics. Exp. Mech., 50, 289-305, 2010.

[29] Olsson, E., Larsson, P.L. A numerical analysis of cold powder compaction based on micromechanical experiments. Powder Technol., 243, 71-78, 2013.

[30] Clément, P. Détermination des propriétés mécaniques de céramiques poreuses par essais de microindentation instrumentée sphérique. $\mathrm{PhD}$ thesis, INSA de Lyon (France), 2013.

[31] Bay, B. K., Smith, T. S., Fyhrie D. P., Saad, M. Digital Volume Correlation: Three-dimensional Strain Mapping Using X-ray Tomography. Exp. Mech., 39, 217-226, 1999.

[32] Smith, T. S., Bay, B. K., Rashid, M. Digital volume correlation including rotational degrees of freedom during minimization. Exp. Mech, 42, 272-278, 2002.

[33] Sutton, M.A. Computer Vision-Based, Noncontacting Deformation Measurements in Mechanics: A Generational Transformation. Appl. Mech. Reviews, 65, AMR-13-1009, 050802, 2013.

[34] Roux, S., Hild, F., Viot, P., Bernard, D. Three-dimensional image correlation from X-ray computed tomography of solid foam. Comp. Part A 39, 1253-1265, 2008.

[35] Leclerc, H., Périé, J.-N., Roux, S., Hild, F. Voxel-Scale Digital Volume Correlation. Exp. Mech., 51(4), 479-490, 2011.

[36] Leclerc, H., Périé, J.-N., Hild, F., Roux, S. Digital Volume Correlation: What are the limits to the spatial resolution? Mech. E Indust., 13, 361$371,2012$. 
[37] Taillandier-Thomas, T., Roux, S., Morgeneyer, T.F., Hild, F. Localised strain field measurement on laminography data with mechanical regularization. Nucl. Inst. Meth. Phys. Res. Sect. B, 324, 70-79, 2014.

[38] Hild, F., Fanget, A., Adrien, J., Maire, E., Roux, S. Three dimensional analysis of a tensile test on a propellant with digital volume correlation. Arch. Mech., 63(5-6), 1-20, 2011.

[39] Hild, F., Bouterf, A., Roux, S. Damage measurements via DIC. Int. J. Fract., 191(1), 77-105, 2015.

[40] Mulhearn, T.O. The Deformation of Metals by Vickers-Type Pyramidal Indenters. J. Mech. Phys. Solids, 7, 85-96, 1959.

[41] Bouterf, A., Adrien, J., Maire, E., Brajer, X., Hild, F., Roux, S. Failure Mechanisms of Plasterboard in Nail Pull Test Determined by X-ray Microtomography and Digital Volume Correlation. Exp. Mech., 56, 181-200, 2016. 